\title{
Investigation of the Effects of Flowline Sizes, Flow Rates, Insulation Material, Type and Configuration on Flow Assurance of Waxy Crude
}

\author{
Ifeanyichukwu E. Onyegiri \\ Offshore Technology Institute, University of Port Harcourt, Choba, Port Harcourt, Nigeria \\ Tobinson A. Briggs* \\ Mechanical Engineering, University of Port Harcourt, Choba, Port Harcourt, Nigeria \\ E-mail: tobinson.briggs@uniport.edu.ng \\ Ekwe B. Ekwe \\ Mechanical Engineering, Gregory University, Uturu, Abia State
}

\begin{abstract}
The recovery of hydrocarbons has gone into deep and ultra-deep waters. Typically, operations from such an environment make the system susceptible to flow assurance challenges. Operations with long subsea flowlines need special attention with respect to flow assurance problems, especially with respect to wax deposition and risk of hydrate formation. As a result, during such operations, it becomes very crucial to evaluate the flowline sizes, flow rates and subsea flowline lengths to minimize flow assurance problems. For the wax deposition control, the operating temperature must be maintained above wax appearance temperature (WAT) by either insulation or electrical heating depending on the cost and energy efficiency factors. In this study, several multiphase simulations were carried out using PIPESIM software to investigate the effects of flowline sizes, flow rates, insulation material, type and configuration on flow assurance of waxy crude over $10.2 \mathrm{~km}$ between the wellhead and the first stage separator on the platform. Considering the implications of these factors for flow assurance. The data and results obtained from this study suggest that line size of $0.29 \mathrm{~m}$, the flow rate of $3280 \mathrm{~m}^{3} / \mathrm{d}$, poly-urethane foam, and pipein-pipe insulation type are favourable to flow assurance of waxy crude with respect to maintaining the temperature of the fluids above the wax appearance temperature of $26^{\circ} \mathrm{C}$; and also to deliver the fluids to the platform at the recommended pressure of over 11 bar.
\end{abstract}

Keywords: Waxy Crude. Flow Assurance. Flow Rates. PIPESIM software, wax control.

DOI: $10.7176 /$ ISDE/11-3-02

Publication date: April $30^{\text {th }} 2020$

\section{Introduction}

Oil and gas exploration and production accounts for over 35 per cent of energy sources worldwide, making it a major and crucial source of energy to the world energy mix. (International Energy Agency, 2018). The gradual depletion of onshore hydrocarbon reserves has led to the rapid increase in oil and gas exploration in offshore regions. These regions contain reserves which may be situated in shallow, deep or ultra-deep waters. The advent and increase in offshore and subsea production have come with its peculiar challenges. Factors such as harsh environmental conditions, flow assurance issues, difficulty and cost of the inspection, repair and maintenance of subsea systems amongst others pose challenges to effective, economic and reliable products throughout the economic life of offshore fields (Girma et al., 2018). Flow assurance is a particular issue that affects offshore fields, especially those in deep waters. Flow assurance refers to the guarantee of the flow of hydrocarbon from the wellbore up until the point of sale or processing (Jung et al., 2014; Kang et al., 2014). This is a challenge due to the large water depth from the seabed to the host platform, in cases where a floating platform is utilized, or the long tie-in distances in cases where tie-backs are used to develop such a field. This distance leads to temperature and pressure losses, resulting in reduced velocity and multiphase flow accompanied by the formation of wax and hydrates. Also, the huge temperature differential between the subsurface temperature and the seabed temperature leads to flow assurance issues. This makes flow assurance a major aspect of offshore field development (Hoffmann, 2012).

In recent years, the steady increase in energy demand globally as a result of the development of economies, growth in population and industrialization has led to a corresponding decline in conventional energy sources. It has triggered a shift into nonconventional sources. This is evident even in the oil and gas industry, where declining conventional oil reserves has led to the exploitation of heavy oil sources to augment for this decline. Heavy crude oil is naturally-occurring petroleum compounds that are readily distinguished by their high specific gravities and low American Petroleum Institute (API) gravities. Heavy crude oil has API gravities that fall below $22.3^{\circ}$ and specific gravities in regions greater than 0.92 . They are further characterized by high viscosities, typically in 
regions above 100 centipoises $(\mathrm{cP})$. This characteristic feature makes it difficult to flow naturally, hence creating challenges in the area of crude transportation. However, due to the steady increase in offshore and deep-water projects, the study of wax deposition during heavy crude transportation is receiving more considerable attention and research on ways to overcome this challenge is being undertaken.

Heavy crude oil contains long-chain saturated alkanes, which are prone to cause flow assurances issues like wax and paraffin, asphaltene, hydrates, and scaling during long-distance transportation (Hasan et al., 2010). These compounds become visible in the oil due to temperature drop and form a waxy and elongated crystal. Control of wax deposition needs to be effective to complete prevention of pipeline blockages. Wax appearance temperature (WAT) is the temperature at which crystal begins to form. Below WAT, crystals begin to develop and grow. The crystal can be formed in the flowing fluid, and it is transported along with the fluid in the form of particles or deposited on cold pipe walls where a build-up of crystals would occur (Bai and Bai 2012a). The pour point is the temperature at which oil will solidify into a gel (Bai and Bai 2012b). Wax deposition in subsea transport pipelines is a major flow assurance issue due to two resulting scenarios that can occur from the phenomenon; steady and gradual wax growth and precipitation radially leads to a reduction in flow areas causing unexpected pressure losses and slugging. In the extreme case, when wax growth is left unchecked, it can lead to the total plugging of the pipeline. These scenarios lead to production downtime and extra operating expenses required for remediation activities and unplugging of the flowline. In the worst circumstances, total field shutdown can occur. This was the case of the Staffa field, which was abandoned due to total plugging of the flowline at an evaluated cost in excess of $\$ 100$ million (Bouchonneau et al., 2007). This shows that wax deposition in subsea pipelines is a complex and costly problem for the oil and gas industries. The financial implications can be alarming. Some remediation operations can last over 1.5 months and cost in excess of 30 million dollars. In the Gulf of Mexico, between the years 1992 and 2002, about 51 cases of plugged pipelines due to wax deposition were recorded. Remediation activities on these flowlines cost approximately $\$ 1$ million/mile (Kang et al., 2014). All these make it contingent for measures to be taken to avoid the formation of wax in subsea pipelines and flowlines. Before now, there are limited efforts to investigate the synergistic impact of factors such as flow rate, flowline size, water cut, insulation configuration, overall heat transfer coefficient, slugging, transient operations, etc. on the wax deposition. Sequel to this, this work focuses on analyzing the above factors on waxy crude transportation via multiphase simulations using PIPESIM. This research aim is to design a subsea flowline system to successfully transport fluids from a subsea manifold to a host platform without the formation of wax or hydrates.

\section{Research Data}

For recovered hydrocarbons from deep water wellheads to get to the platform, they have to flow through jumpers, manifolds and risers which are made to operate and withstand deep water pressures, temperatures and strong winds (Bai and Bai, 2005). But, by increasing the subsea tieback distances for a long-distance comes with associated issues. In such adverse operating conditions, there is always a high tendency for wax deposition and other flow assurance issues. These wax deposits can be intense enough to plug fluid transport to the platform. The severity of flow issues is greatly dependent on the hydrocarbon compositions and the prevalent temperature and pressure in the field (Zhang et al., 2016). The in-depth understanding of fluid and flow characteristics, together with thermal analysis is very crucial in developing strategies to manage wax deposition and other flow issues.

Wax is a group of normal paraffin, containing 16 or more carbon atoms that turn into solid crystals at $20{ }^{\circ} \mathrm{C}$. These waxy crystals can agglomerate and grow into a higher molecular crystal, thereby causing deposition in the crude oil system. The temperature at which this happens is known as the wax appearance temperature. The wax deposition tends to plug flow and cause financial losses. Several techniques have been proven to be viable as wax deposition management strategy including thermal methods like heating and insulation, the use of wax inhibitors and pigging which is essentially a remediation strategy (Huang et al., 2015).

This work focuses on the multiphase simulation of waxy crude in a subsea flowline to analyze and be able to predict and manage wax deposition and other flow assurance challenges prevalent in subsea operations. The subsea flowline being simulated is designed to flow produced hydrocarbons from a subsea manifold to a host platform. The production rate during maximum, normal and turndown scenarios are given as 1640, 2460 and 3280 sm3/day, respectively. Dry oil and associated gas with no significant water are expected for the first three years. The wellhead temperature varies between $45-50{ }^{\circ} \mathrm{C}$, and the inlet pressure at the wellhead is $25 \mathrm{bar}$. The outlet pressure at the platform must be 11 bar and above if flow must be achieved. The 1 st stage separator at the platform is designed with an $8.5 \mathrm{~m}^{3}$ slug handling capacity. The wax deposition has been predicted to occur at temperatures below $26^{\circ} \mathrm{C}$. The aim is to prevent wax deposition by using appropriate insulation material for the Flowline (Schlumberger, 2011). The need for the gas lift will be determined in the course of the work. To analyze the effects of critical parameters, including thermal insulation on the wax deposition, a steady-state simulator "PIPESIM" would be utilized.

The multiphase fluids flow through flowline of $10 \mathrm{~km}$ before getting to a $200 \mathrm{~m}$ riser. The riser connects to the platform. The project data was obtained from a field drilled in Africa. This field will be designated as Field X 
in this report. The hydrocarbon properties for Oil X are contained in the project base data alongside operation constraints that must be adhered to.

Table 1: PIPESIM Project Base Data

\begin{tabular}{|c|c|c|c|}
\hline \multicolumn{4}{|l|}{ Manifold / Well Data } \\
\hline Temperature & \multicolumn{2}{|l|}{$45-50^{\circ} \mathrm{C}$} & \\
\hline Pressure & \multicolumn{2}{|l|}{25 bars } & \\
\hline \multicolumn{4}{|l|}{ Flow Line Data } \\
\hline Rate of Undulations & \multicolumn{2}{|l|}{0} & \\
\hline Horizontal Distance & \multicolumn{2}{|l|}{$10,000 m$} & \\
\hline Available Internal Diameters & \multicolumn{2}{|c|}{$0.24 m, 0.29 m, 0.34 m$} & \\
\hline Pipe wall thickness & \multicolumn{2}{|l|}{$0.013 m$} & \\
\hline Pipe roughness & \multicolumn{2}{|l|}{$0.025 \mathrm{~mm}$} & \\
\hline Pipeline Thermal Conductivity & \multicolumn{2}{|c|}{$45 \mathrm{~W} \cdot \mathrm{m}^{-10} \mathrm{C}^{-1}$} & \\
\hline Minimum Outlet Pressure & \multicolumn{2}{|l|}{11 bar } & \\
\hline Maximum Pipeline Outer Diameter & \multicolumn{2}{|l|}{$460 \mathrm{~mm}$} & \\
\hline Ambient Temperature & \multicolumn{2}{|c|}{$5^{0} C$, Sea Water } & \\
\hline Wax Appearance Temperature & \multicolumn{2}{|l|}{$26^{\circ} \mathrm{C}$} & \\
\hline \multicolumn{4}{|l|}{ Riser Data } \\
\hline Elevation & \multicolumn{2}{|l|}{$+200 m$} & \\
\hline Available Internal Diameters & \multicolumn{2}{|c|}{$0.24 m, 0.29 m, 0.34 m$} & \\
\hline Pure Hydrocarbon Components & & & \\
\hline Components & Mole\% $\%$ & & \\
\hline Methane & 36.50 & & \\
\hline Ethane & 4.40 & & \\
\hline Propane & 2.60 & & \\
\hline Isobutane & 0.63 & & \\
\hline Butane & 0.13 & & \\
\hline Isopentane & 0.67 & & \\
\hline Pentane & 0.83 & & \\
\hline Hexane & 2.70 & & \\
\hline Petroleum Fraction & & & \\
\hline Boiling Point ${ }^{\circ} \mathrm{C}$ & Molecular Weight & Specific gravity & Moles \\
\hline 101.1 & 115 & 0.683 & 51.54 \\
\hline Aqueous Component & & & \\
\hline Water & $0 \%$ at initic & onditions but late & ased to $85 \%$ \\
\hline
\end{tabular}

\section{PIPESIM Description}

PIPESIM is a steady-state software and multiphase transport simulator used in the design, forecast and 'diagnostic' analysis of hydrocarbon production systems.

PIPESIM software simulates multiphase flow from the reservoir through the wellhead to the platform. PIPESIM also diagnoses a pipeline, other production equipment and analyses surface facility performance to give a detailed forecast on a production system (Schlumberger, 2011).

PIPESIM would be used in the selection of a suitable flowline diameter that will meet the outlet delivery pressure of not less than 11 bars. To achieve this: the flow model will be developed, and the flowline diameters will be utilized as sensitivity parameters while varying the flow rates. All the steps, taken to design for continued flow between the manifold and the platform are detailed in the steps below.

\subsection{Developing the model}

The flow model illustrates the proposed field layout detailing each component. This process is shown in Figure 1. It involves:

- Select the Insert tab under Network Tools bar and input a source/manifold, flow line/subsea tieback, the junction (for the riser base), a riser, and a sink (platform).

- $\quad$ Connect each object starting from the source to the sink

- Name each object appropriately and differentiate each object with the specific information as stated in the base data table (see Table 1)

After developing the flow model, assign any missing properties to each model object, Oil X should be the fluid assigned to the Subsea Manifold. After these initial tasks, the main tasks can be started using the stepwise approaches to analyse the problems as enumerated under the methods (Schlumberger, 2011). 


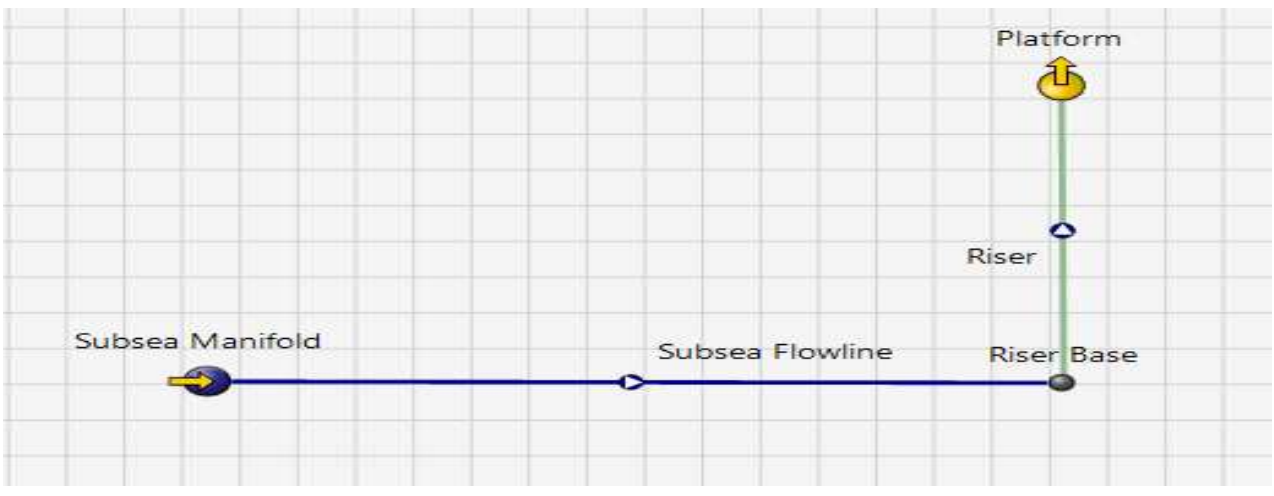

Figure 1: The PIPESIM Flow Model

\section{Methodology}

In designing the flowline, the following tasks shall be carried out as outlined below:

\section{Task 1: To size the flow line and pressure-distance profile analysis for the given flow rates}

The available flowline sizes, that is, for the subsea pipeline and the riser are given to be $0.24 \mathrm{~m}, 0.29 \mathrm{~m}$, and $0.34 \mathrm{~m}$. This only applied to the pipeline diameter and does not affect any other layers. An appropriate internal diameter (ID) for the flowlines, required to maintain the delivery pressure above 11 bar must be determined. It must do so for all production scenarios (maximum, normal and minimum). In this case, the flowline diameters need to be sensitivity parameters in our iterations. The steps for executing this are detailed below:

i. $\quad$ Under Set up > Flow correlations tab, choose the Beggs and Brill revised correlations for both vertical and horizontal flows

ii. Under Operations, $>$ System Analysis and Pressure-Temperature profile, carry out a system analysis with the given flow rates as the $\mathrm{X}$-axis parameter and the given internal diameters as the sensitivity parameters

iii. Simulate with the model and obtain the minimum line $I D$ that meets the required outlet pressure of $11 \mathrm{bar}$ criteria for the maximum flow rate of $3280 \mathrm{~m}^{3} /$ day (Schlumberger, 2011).

Task 2: Determine that the selected line ID does not cause Erosional Velocity:

To do this: the Erosional Velocity maximum needs to be estimated using the API RP 14E formula;

$V_{m}^{*}=1.22 * \frac{c}{\sqrt{ } \rho_{m}}$

Where:

$V_{m}^{*}$ is Erosional Velocity maximum $(\mathrm{m} / \mathrm{s})$

$\mathrm{C}=100$,

$\rho_{m}=$ mixture density $\left(\mathrm{kg} / \mathrm{m}^{3}\right)$ and is provided in PIPESIM output file.

To confirm that a flowline does not have issues with erosion, the maximum erosional velocity ratio, EVR must be less than one (1).

Task 3: Estimate the hydrate formation temperature and determine the Overall Heat Transfer Coefficient (OHTC), $U$ for the line:

This involves iterations with Katz charts at a constant pressure of 25 bar, changing temperatures and estimating $K$ values for $C 1, C 2, C 3, I C 4$ and $n C 4$. The hydrate formation temperature is the temperature that results in:

Where,

$$
\sum(y / K)=1
$$

$y$ is the vapour mole fractions of the components gotten from PIPESIM. These components, that is: $C 1, C 2, C 3$, IC4 and $n C 4$ have infinite $\mathrm{K}$ values (David, 2013).

The hydrate formation temperature and Wax Appearance Temperature will be weighed against each other, and the greater of the two will be utilised as the minimum outlet temperature. A safety margin of $4{ }^{\circ} \mathrm{C}$ will be added to the WAT, making it $30^{\circ} \mathrm{C}$. The overall heat transfer coefficient is obtained through equation (3) below.

$U=\frac{\left(m * C_{p n}\right)}{A} * \operatorname{In}\left[\left(T_{1}-t_{1}\right) /\left(T_{2}-t_{1}\right)\right]$

Where,

$m=$ mixture mass flow rate $(\mathrm{kg} / \mathrm{s})$,

$C_{p n}=$ mixture Specific Heat capacity $\left(\mathrm{J} \mathrm{Kg}^{-1}{ }^{\circ} \mathrm{C}^{-1}\right)$,

A = external flowline area $\left(\mathrm{m}^{2}\right)$,

$T_{1}=$ Inlet temperature of the pipe/flowline $\left({ }^{\circ} \mathrm{C}\right)$

$T_{2}=$ Outlet temperature of the pipe/flowline $\left({ }^{\circ} \mathrm{C}\right)$ 
$t_{1}=$ Surrounding flowline temperature, that is, seabed temperature $\left({ }^{\circ} \mathrm{C}\right)$.

$C_{p n}$ is obtained from the following equation:

$C_{p n}=\left(C_{p l} * H_{l}\right)+\left(C_{p g} *\left(1-H_{l}\right)\right)$

$A=\pi D_{o} L$

$D_{o}=D_{i}+2(t)$

Where

$C_{p g}=$ Gas Specific Heat capacity $\left(\mathrm{J} \mathrm{Kg}^{-1}{ }^{\circ} \mathrm{C}^{-1}\right)$

$C_{p l}=$ Liquid Specific Heat capacity $\left(\mathrm{J} \mathrm{Kg}^{-1}{ }^{\circ} \mathrm{C}^{-1}\right)$

$H_{l}=$ Liquid Holdup

$D_{o}=$ Flowline outer diameter

$D_{i}=$ Inner diameter of flowline

$t=$ flowline wall thickness

$L=$ Length of the Flowline

m, $H_{l}, C_{p g}$, and $C_{p l}$ will be obtained from the PIPESIM output file.

Task 4: Establish a suitable Insulation Configuration to keep the fluids above wax appearance temperature and prevent wax deposition:

Using the estimated overall heat transfer coefficient: $U\left(\mathrm{~W} \mathrm{~m}^{-2}{ }^{\circ} \mathrm{C}^{-1}\right)$, an appropriate insulation type and material would be suggested, and this depends on the value $U$. The suitable correlation will be utilized to obtain the needed insulation thickness based on the type of Insulation system and material appropriate to obtain the calculated $U$. Simulations will be carried out to determine the appropriate insulation thickness that will keep the fluids above the WAT during the lifetime of the field.

Analytical calculations will guide our initial guess for the thickness required for wax-free flow.

Task 5: Validate the suitability of the slug catcher capacity for the first stage separator and confirm the probability of severe slugging:

With Brill, Beggs, and Mukherjee correlation,

$\ln \left(L_{m}\right)=-2.663+5.441[\ln (d)]^{0.5}+0.059\left[\ln V_{m}\right]$

Where,

$L_{m}=$ Average slug length in feet.

$\mathrm{d}=$ Line internal diameter (inches)

$V_{m}=$ Mixture velocity $(\mathrm{ft} / \mathrm{sec})$.

$$
V_{m}=V_{s l}+V_{s g}
$$

$V_{s l}$ and $V_{s g}$ are the velocities of the liquid and gas phases respectively and are gotten from PIPESIM. The average length of slug will be multiplied by the area of flowline in order to estimate the slug volume (Yukie, 2014). If the calculated volume is less than the slug catcher capacity of the separator of $8.5 \mathrm{~m}^{3}$, the catcher capacity is appropriate, if not, it is not appropriate and requires further work.

The conditions for severe slugging will be evaluated too. The requirements include (Yukie, 2014):

1) Topography: the flowline should have an elevation drop on approaching the riser.

2) Flow Pattern: the flow must be stratified on getting to the riser. The flow pattern will be determined from PIPESIM.

3) The severe slugging number $\prod_{s S}<1$.

This is estimated using the formula given below.

$$
\Pi_{s s}=\frac{|d P / d t|_{\text {pipe }}}{\left|d P / d t_{\text {riser }}\right|}=\frac{\left(Z_{m} * R * T / M_{*}\right)}{\left|g * L_{\text {pipe }} *\left(1-H_{l}\right) * G_{l}\right|}=\left|\frac{P * U_{s g}}{g * L_{\text {pipe }} *\left(1-H_{l}\right) * \rho_{l} * U_{s l}}\right|
$$

where,

$P=$ inlet pressure,

$\mathrm{g}=$ acceleration due to gravity

$\mathrm{U}_{\mathrm{sg}}=$ gas superficial velocity $(\mathrm{m} / \mathrm{s})$

$\mathrm{U}_{\mathrm{sl}}=$ liquid superficial velocities $(\mathrm{m} / \mathrm{s})$

$\rho_{l}=$ liquid density $\left(\mathrm{kg} / \mathrm{m}^{3}\right)$

$H_{l}=$ Liquid Holdup

$\mathrm{U}_{\mathrm{sl}}, \mathrm{U}_{\mathrm{sg}}, H_{l}$, and $\rho_{l}$ would all be gotten from PIPESIM.

Task 6: Confirm if Gas Lift will be needed when the volume of water is $85 \%$.

This will be determined with done with PIPESIM by doing the following:

- Using $85 \%$ as the volume ratio of water under set-up compositional local default

- Input the appropriate flow rate, click Pressure-Distance in Pressure-Temperature profile under operations and then simulate. If the pressure is less than 11 bara in Pressure-Distance profile plot, then the gas lift is required (Schlumberger, 2011). 


\section{Results and Discussion}

\subsection{Phase Envelope for Oil $X$}

Using the available data: the hydrocarbon was flashed using the Fluid Manager on PIPESIM. The phase envelope developed for Oil X is seen in Figure. 2.

\subsection{Selection of appropriate flowline internal diameter (ID)}

The actual outputs of the pressure-distance profile obtained from PIPESIM simulation for the various flowline IDs are shown in the Figure. 3. PIPESIM outputs from the plot of system outlet pressure against flow rate show that line size of $0.24 \mathrm{~m}$ ID will not deliver the fluid to the platform at a pressure above $11 \mathrm{bar}$ using a flow rate of 3280 $\mathrm{Sm}^{3} /$ day and hence does not meet the delivery pressure requirement. Line sizes of $0.29 \mathrm{~m}$ and $0.34 \mathrm{~m}$ were the two options remaining for consideration, but for economics, it will be more economical to use $0.29 \mathrm{~m}$. In summary, 0.24 and $0.34 \mathrm{~m}$ line sizes were eliminated. The results specify the delivery pressure for each flowline and at each production scenario. The flowlines are used as sensitivity parameters against the various maximum, normal and minimum flow scenarios.

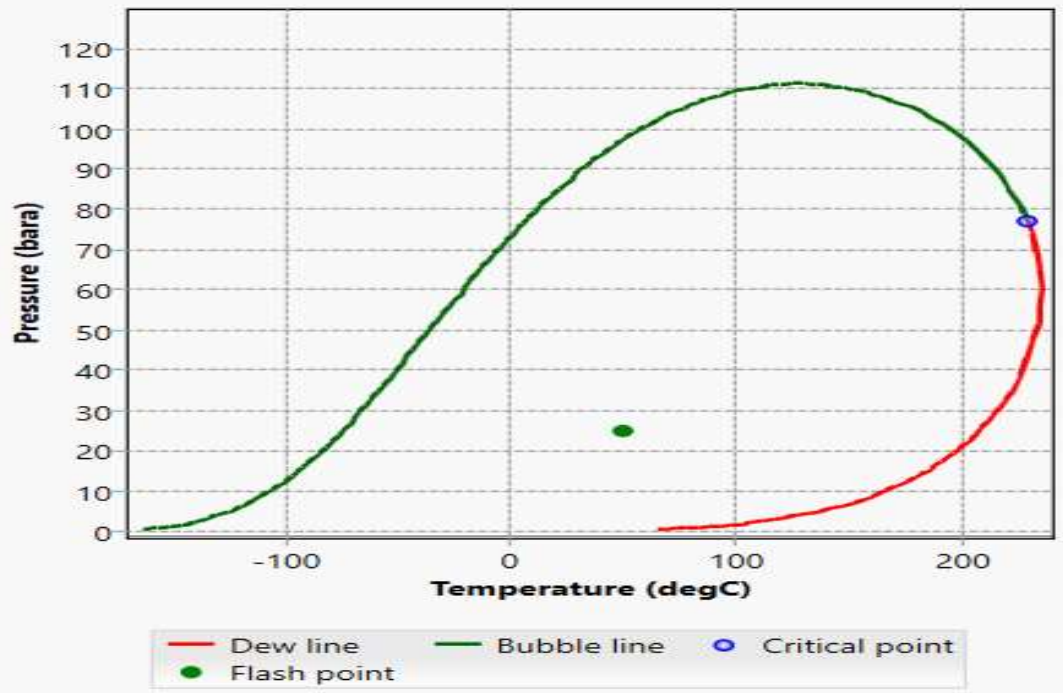

Figure 2: Phase Envelope for Oil X
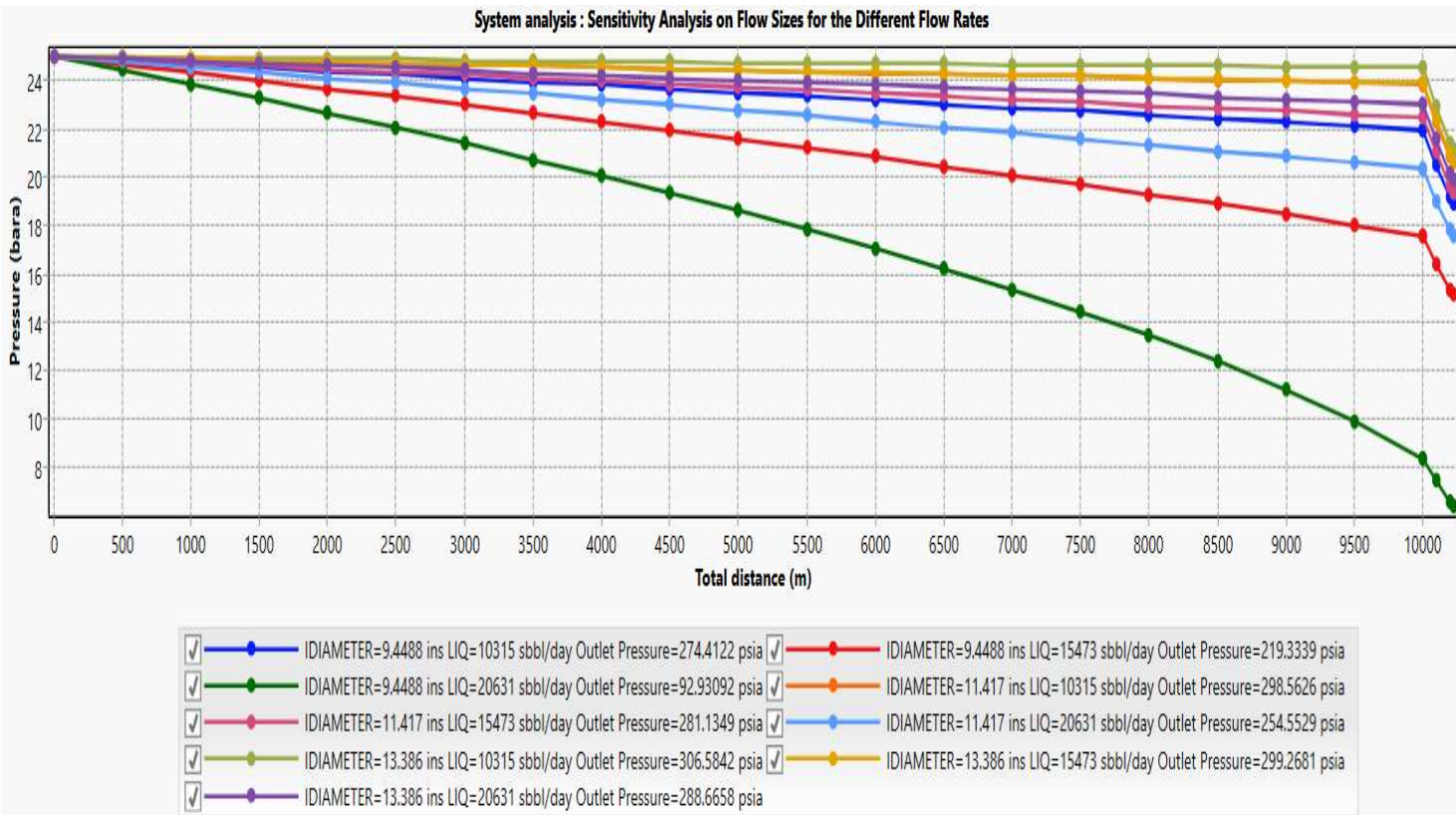

Figure 3: Delivery pressure against total distance for all the flowline sizes

Fig. 4.2 shows that the flowline sizes that will meet the delivery pressure requirements are $0.29 \mathrm{~m}$ and $0.34 \mathrm{~m}$. 
The $0.24 \mathrm{~m}$ flowline will not achieve this when the field is operating maximum flow rate of $3280 \mathrm{Sm}^{3} / \mathrm{day}$. This means the $0.24 \mathrm{~m}$ flowline will be rejected as an option for Field X.

Figure 3 shows that the flowline sizes that will meet the delivery pressure requirements are $0.29 \mathrm{~m}$ and $0.34 \mathrm{~m}$. The $0.24 \mathrm{~m}$ flowline will not achieve this when the field is operating the maximum flow rate of $3280 \mathrm{Sm}^{3} / \mathrm{day}$. This means the $0.24 \mathrm{~m}$ flowline will be rejected as an option for Field X.

\subsection{Erosion Screening}

The summary of the output for Maximum Erosional Velocity Ratio using the API RP 14E correlation is as given in Figure 4 using PIPESIM generated data. PIPESIM outputs from the plot of Erosional velocity ratio Vs Flow Rate shows that the line ID of $0.24 \mathrm{~m}$ does not meet the API RP 14E erosion criteria because the erosional velocity maximum ration is greater than 1 . Still, both line IDs of $0.29 \mathrm{~m}$ and $0.34 \mathrm{~m}$ met the erosion criteria because their erosional velocity maximum ratios were less than 1 . However, the maximum erosional velocity ratio for IDs of $0.29 \mathrm{~m}$ and $0.34 \mathrm{~m}$ estimated with PIPESIM gave a higher limit of $0.10 \mathrm{~m}$ and $0.07 \mathrm{~m}$ at a flow rate of $820 \mathrm{sm}^{3} / \mathrm{d}$ compared to the calculated maximum erosional velocity which gave $0.152 \mathrm{~m}$; this means that the line ID of $0.34 \mathrm{~m}$ is better in terms of erosion.

System analysis : Sensitivity Analysis on Flow Sizes for the Different Flow Rates

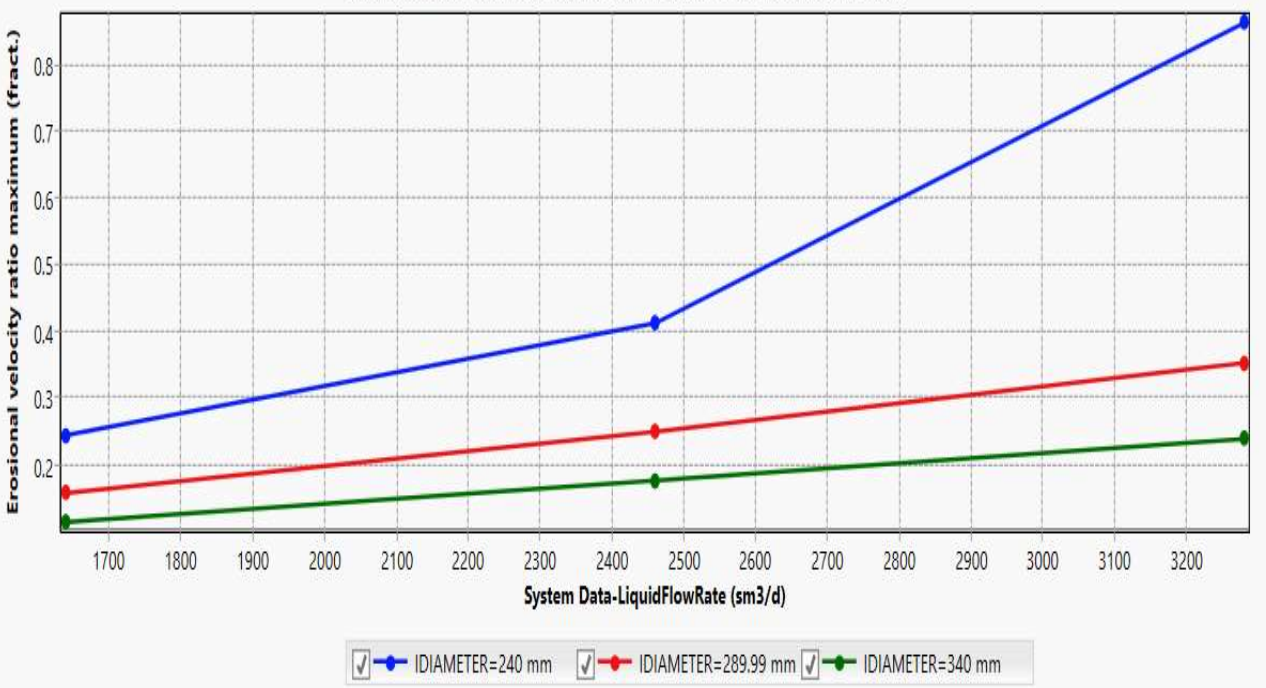

Figure 4: Erosional velocity ratio maximum against the various flow rates

\subsection{The Hydrate formation temperature (HFT)}

The HFT was estimated using Katz correlation outlined in equation 2. Microsoft Excel was used to carry out the iterations. The wellhead pressure of 25 bar was used to estimate the minimum temperature below which hydrate formation will occur because ideally, hydrates appear at high pressure. Joule Thompson expansion and cooling at the inlet was considered as well. After iterations and interpolation using equation (2), the hydrate formation temperature was obtained to be $11.43{ }^{\circ} \mathrm{C}$. It is proven that at a lower overall heat transfer coefficient, lower temperature drop in the flowline is experienced. From the Katz chat, hydrate formation temperature of $11.43^{\circ} \mathrm{C}$ was estimated and using a pressure of 25 bar, a value of $U=2.60079 \mathrm{~W} / \mathrm{m}^{20} \mathrm{C}$ was estimated with PIPESIM, these values met the hydrate formation conditions for the gas compositions. The wax appearance temperature of $26^{\circ} \mathrm{C}$, with a safety factor of $4^{\circ} \mathrm{C}$ added, was used as the temperature for estimating $\mathrm{U}$, which gave a value of $0.81 \mathrm{~W} / \mathrm{m}^{2}{ }^{\mathrm{O}} \mathrm{C}$. A safety factor of $4^{\mathrm{O}} \mathrm{C}$ was added to keep the flow line out of the hydrate formation and wax deposition zones

\subsection{Selection of insulation material, thickness and configuration}

Given that the WAT was obtained through experimental studies to be $26^{\circ} \mathrm{C}$, the temperature of the fluid stream must be kept above $30^{\circ} \mathrm{C}$ for safe operations without wax deposition. Simulations were carried out to determine the temperature drop for the uninsulated pipeline with only a concrete coating. The variation of temperature with distance is given in Figure. 5. Polyurethane foam insulation with thermal conductivity of $0.03 \mathrm{~W} / \mathrm{moC}$ was selected. After simulations, insulation thickness of $0.015 \mathrm{~m}$ was obtained to maintain the required temperature using the PIPESIM simulation. 


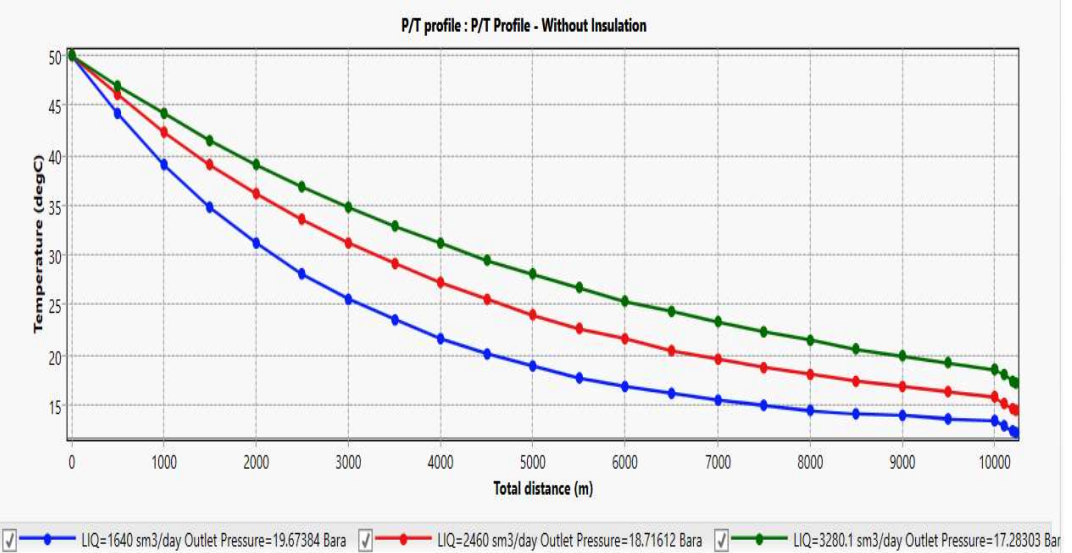

Figure. 5: Temperature drop across the flowline for uninsulated pipeline

The graph shows that without insulation, the hydrocarbon stream will fall below the hydrate and wax appearance temperatures. The various insulation pipe configurations into Consideration, Pipe-in-Pipe configuration was chosen. It is worthy of note to mention that the insulation chosen will apply to both the subsea flowline and riser. In selecting an appropriate insulation material, simulations were carried out. The constraint for this selection was the overall outside diameter, which should be less than or equal to $460 \mathrm{~mm}$. Knowing that a concrete coating of $40 \mathrm{~mm}$ thickness is to be applied unto the main insulant, this leaves the required insulation thickness to be at most less than or equal to $32 \mathrm{~mm}$. Two insulation materials were considered. These were Polyurethane Foam (PUF) with thermal conductivity of $0.03 \mathrm{~W} \mathrm{~m}^{-2}{ }^{\circ} \mathrm{C}^{-1}$ and Polypropylene Reinforced (PPPR) with a k value of $0.08 \mathrm{~W} \mathrm{~m}^{-2}{ }^{\circ} \mathrm{C}^{-1}$. Considering Polypropylene Reinforced with an insulation thickness of $25 \mathrm{~mm}$, we had the following temperature drop, as shown in Figure 6.

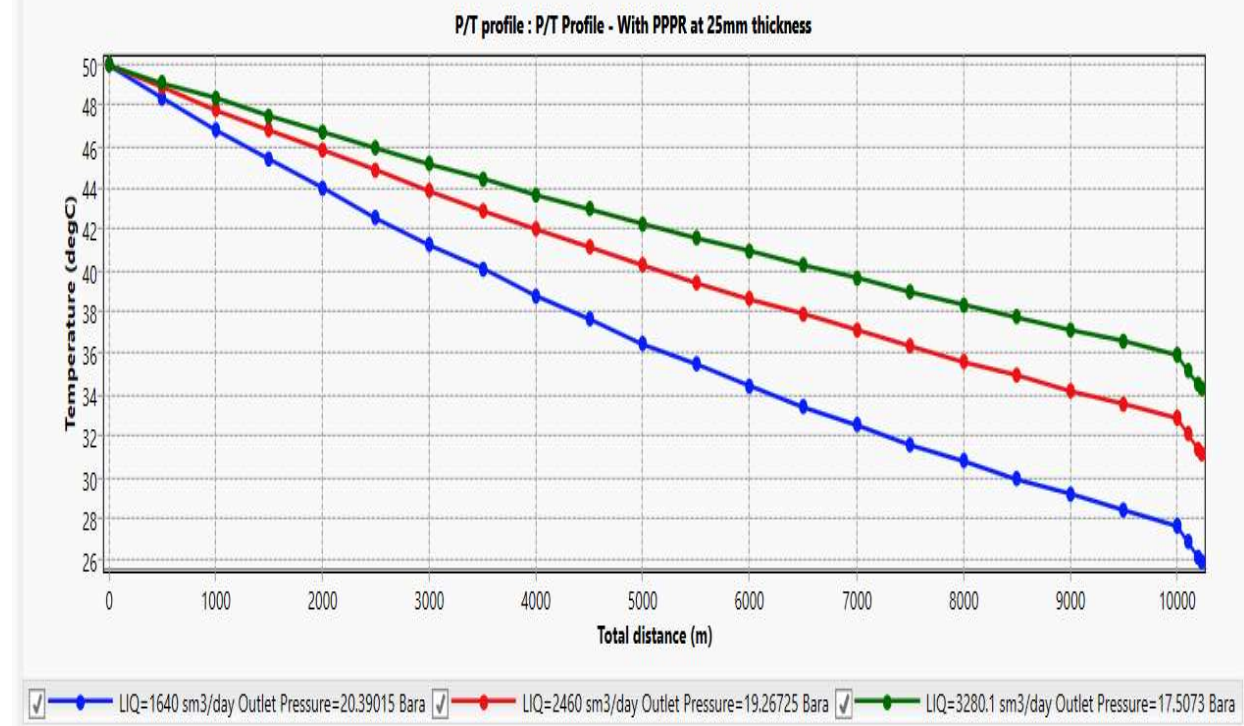

Figure 6: Temperature drop across the flowline insulated with Polypropylene Reinforced (25mm thickness) 


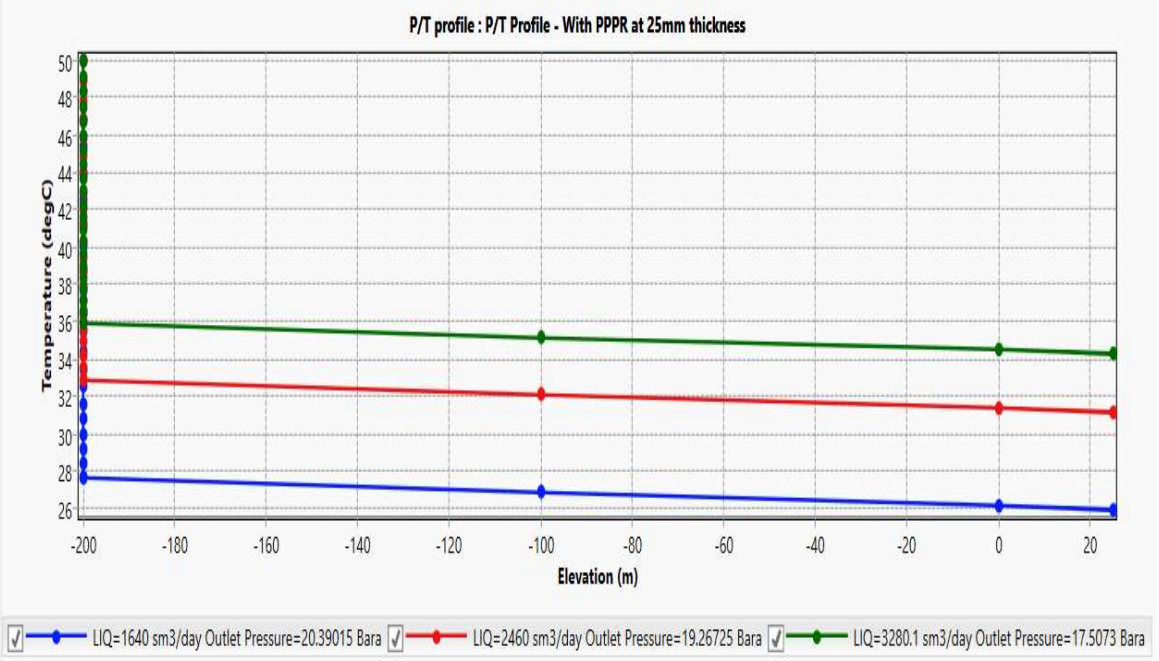

Figure 7: Temperature drop along the riser insulated with Polypropylene Reinforced (25mm thickness)

WAT. There is a slight drop below WAT at the riser base and in the riser. The plot showing the drop along the marine riser is shown in Figure 7. It was observed that the fluid gets to the platform at approximately $26{ }^{\circ} \mathrm{C}$, which is the WAT. Although this is sufficient, it does not meet the safety margin criteria of $30^{\circ} \mathrm{C}$. Due to this fact, the insulation thickness for the PPPR was increased to $30 \mathrm{~mm}$ and simulation was carried out. Figure 8 shows the temperature drop across the subsea pipeline under these conditions.

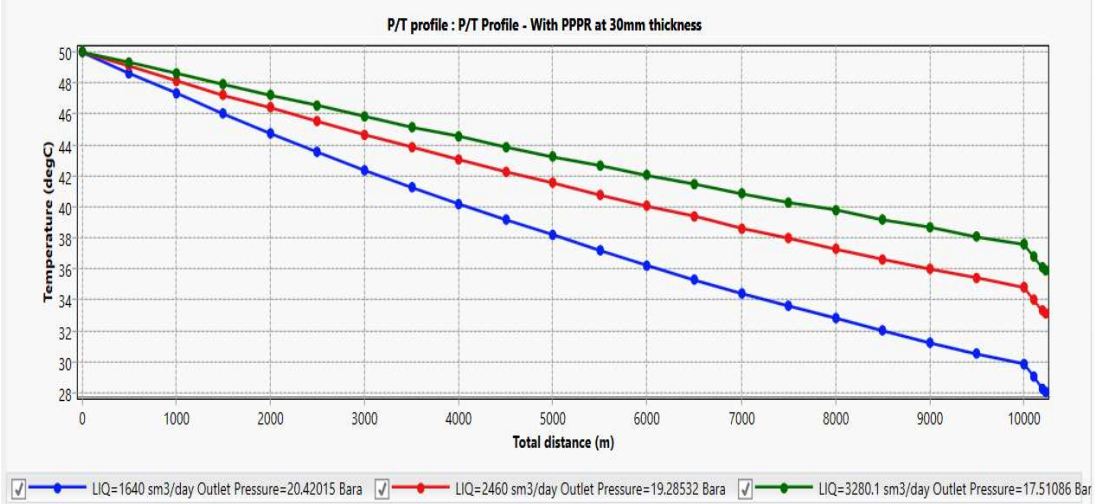

Figure 8: Temperature drop across the flowline insulated with Polypropylene Reinforced (30mm thickness)

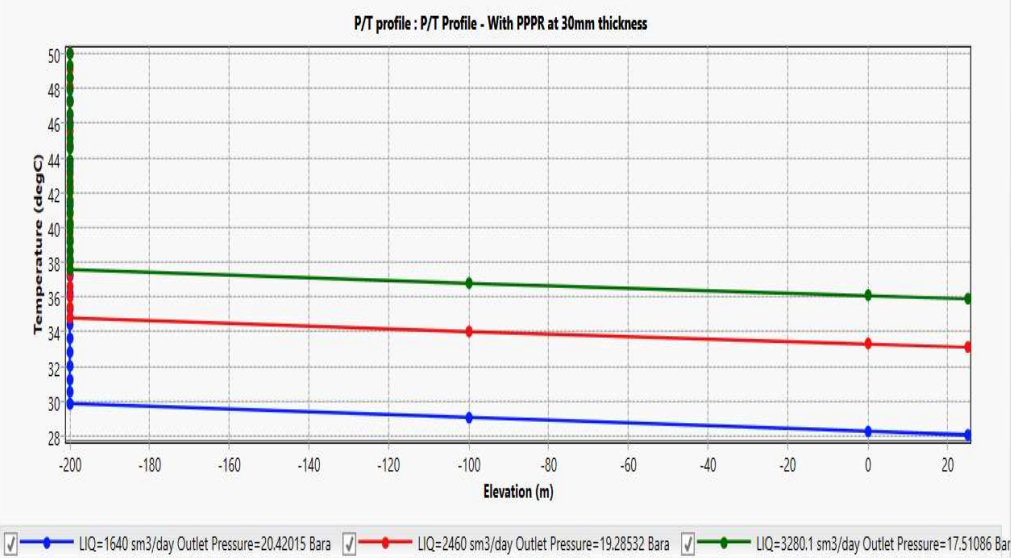

Figure 9: Temperature drop along the riser insulated with Polypropylene reinforced (30mm thickness)

Considering $30 \mathrm{~mm}$ thickness of PPPR, it is insufficient to escape the safe operation region of $30^{\circ} \mathrm{C}$. This is further buttressed by the plot for the temperature drop along the marine riser. This is shown in Figure 9 . The arrival 
temperature at the platform is $28^{\circ} \mathrm{C}$ which is sufficient but does not satisfy the safe operating temperature of $30^{\circ} \mathrm{C}$. The next insulation material to consider was Polyurethane Foam (PUF). Considering PUF with a $15 \mathrm{~mm}$ insulation thickness, we obtain the plots for temperature drop across the pipeline and along the marine riser.

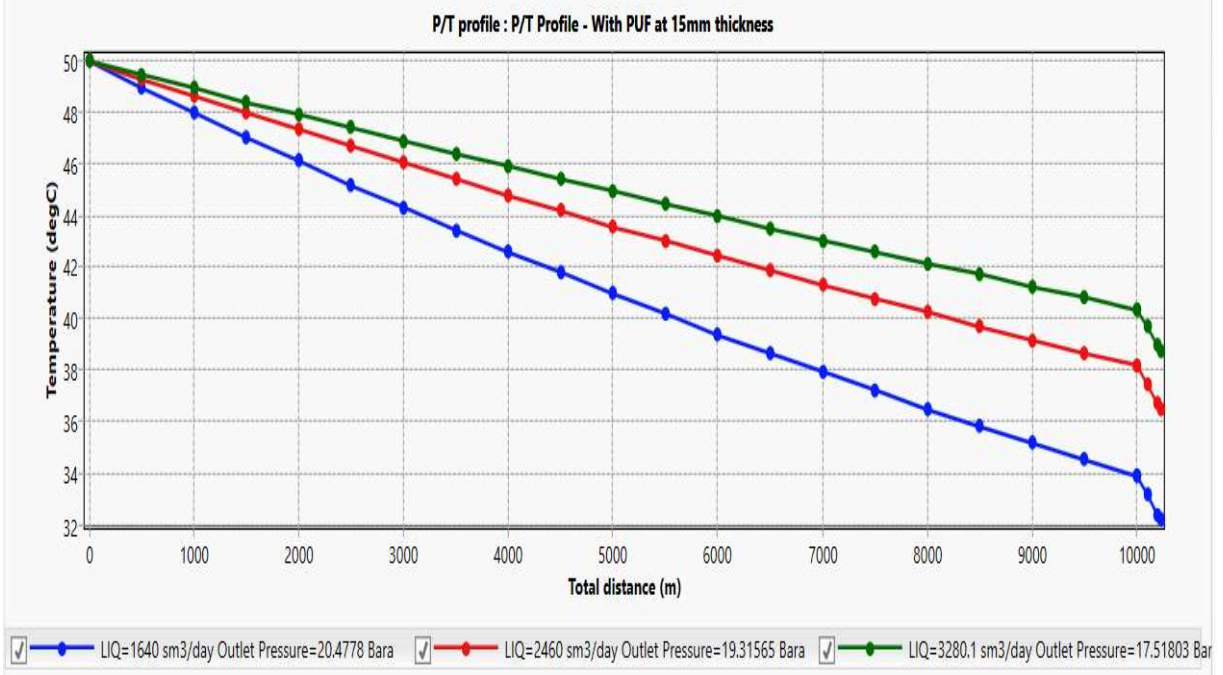

Figure 10: Temperature drop across the flowline insulated with Polyurethane Foam (15mm thickness)

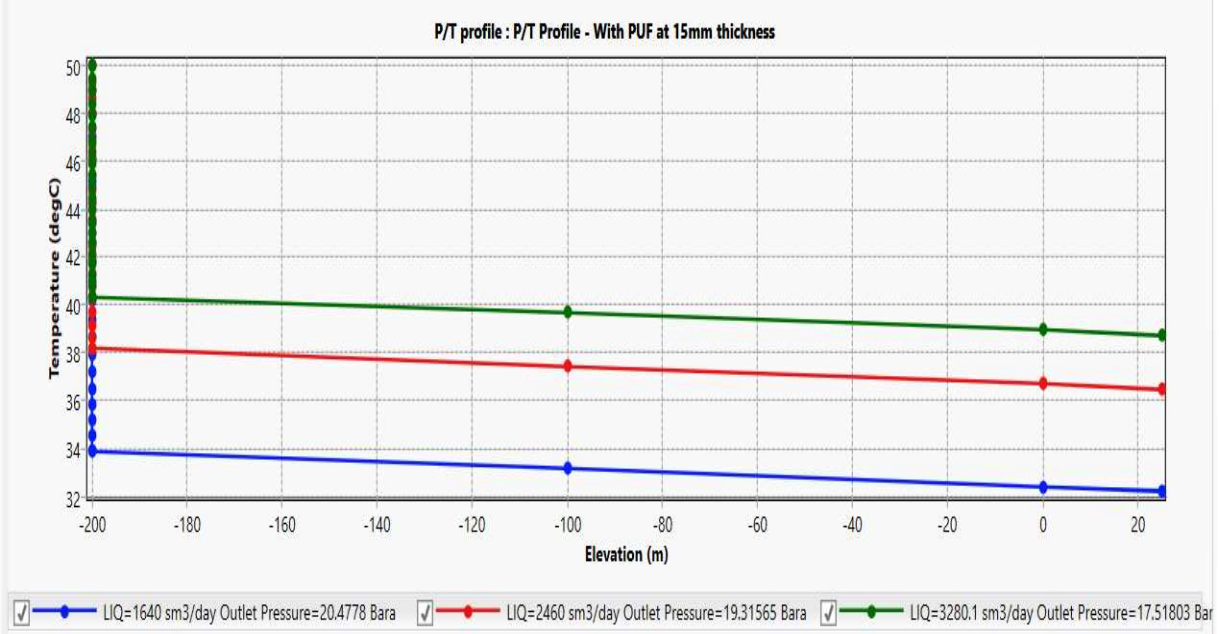

Figure 11. Temperature drop along the riser insulated with Polypropylene Reinforced (25mm thickness)

Figures 10 and 11 show that PUF of $15 \mathrm{~mm}$ thickness is sufficient for safe operation above the WAT and safe operating temperature of $30^{\circ} \mathrm{C}$. This is chosen as it drastically reduces the overall pipeline diameter and therefore, installation costs. Poly-Urethane is utilized as the insulation material because of its very low thermal conductivity ( $K$ of $0.03 \mathrm{~W} \mathrm{~m}^{-2}{ }^{\circ} \mathrm{C}^{-1}$ ). The least flow rate of $1640 \mathrm{sm}^{3} /$ day was also satisfied by this insulation since it is the flowrate with the highest tendency of causing excessive temperature loss. The insulation material, configuration and thickness are detailed in Table 2.

Table 2: System Insulation Configuration Output from PIPESIM

\begin{tabular}{ll}
\hline Insulation Type & Pipe-in-Pipe System \\
\hline Insulation Material & Poly-Urethane Foam \\
Thermal Conductivity of Material, $k$ & $0.03 \mathrm{~W} \mathrm{~m}^{-2} \mathrm{C}^{-1}$ \\
Required Insulation Thickness & $0.015 \mathrm{~m}$ \\
\hline
\end{tabular}

\subsection{Terrain induced slug estimation}

This is executed using Scott, Shoham and Brill correlation. This method was used to estimate the length and volume of the slug, as shown in Table 3, and the tendency for severe slugging is determined. 
Table 3: Length, Volume and Severe slugging Number for the highest and lowest flowrates

\begin{tabular}{llll}
\hline Flow Rates & Length of Slug $(\mathrm{m})$ & The volume of Slug $\left(\mathrm{m}^{3}\right)$ & Severe Slugging number \\
\hline $1\left(1640 \mathrm{sm}^{3} / \mathrm{d}\right)$ & 153.677 & 7.010 & 0.19 \\
\hline \hline $4\left(3280 \mathrm{sm}^{3} / \mathrm{d}\right)$ & 116 & 7.82 & 0.29 \\
\hline
\end{tabular}

The average Slug Lengths $(\mathrm{m})$ and Volumes $\left(\mathrm{m}^{3}\right)$, Flow Patterns on Approaching the Riser and Severe Slugging Numbers for the flow rate of $3280 \mathrm{sm}^{3} /$ day are given in Table 4.

Table 4: Mean slug length, volume and slugging number for the flow rate of $3280 \mathrm{sm} 3 /$ day

\begin{tabular}{ll}
\hline Property & Value \\
\hline Flow rate & $3280 \mathrm{sm}^{3} /$ day \\
Slug Length & $135 \mathrm{~m}$ \\
Slug Volume & $7.42 \mathrm{~m}^{3}$ \\
Flow Pattern & Intermittent \\
Severe Slugging Number $\prod_{s s}$ & 0.24 \\
\hline
\end{tabular}

\subsection{Field $X$ late-life considerations}

Considering the fact that in late life of field there will be increased water cut of $85 \%$, modelling was done to reflect on the effect of this increase towards the formation of waxes and hydrates. The phase envelope changes with this great increase in water cut. Investigations are also into this. Figure 12 shows the Phase Envelope at the late-life of Field X. The system outlet temperature at $85 \%$ of water volume for the different line sizes is shown in Table 5 .

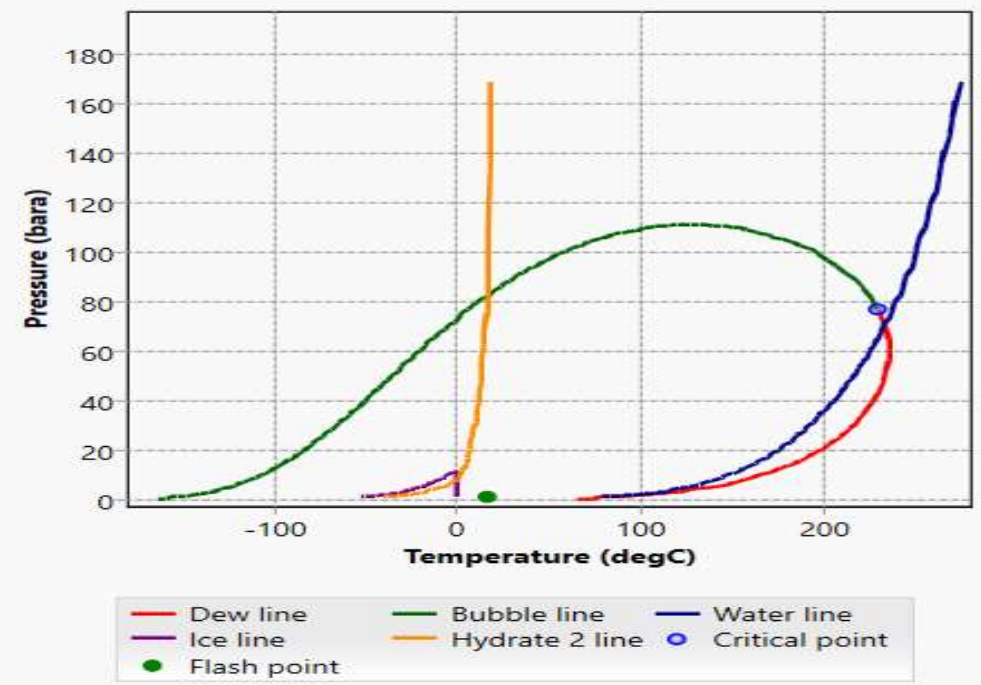

Fig. 12: Phase Envelope showing Hydrate Line at $85 \%$ water cut

Table 5: Outlet pressure of the different line sizes and flow rates at $85 \%$ water volume

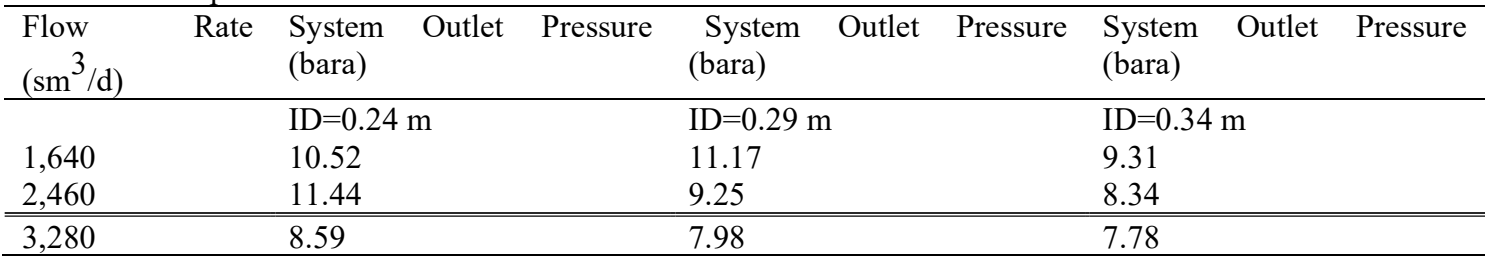

There are some operational modes which have to be effectively considered before finalizing the pipeline architecture, and they include:

1. Blowdown: To keep the flowline system out of the wax appearance zone. This condition will happen; when the shut-in time is longer than the cool-down period, the blowdown process is an option. But, the blowdown rate should be limited to prevent Joule Thompson cooling downstream of the blowdown valve, and prevent brittle fracture of the flowline.

2. Warm-up: During the warm-up process, to avoid the wax appearance temperature at every location, a wax inhibitor must be injected until the temperature is exceeded. Hot oiling also warms up the flowline, resulting in a much longer cool down periods during the warm-up process as compared to warming up with produced fluids. 
3. Turndown: flow rate reduction will lead to an accompanying drop in temperature, which in turn leads to wax formation.

4. Shutdown: shutdown instances include planned and unplanned shutdown from steady-state, and sometimes unplanned shutdown during warm-up. But for Planned shutdown, wax inhibitors should be injected into the system before shut down. During the Shutdown process, flowline will experience low temperature towards ambient conditions, causing wax formation; and can also encounter instability at start-up. The insulation design of "no-touch time" should be integrated into the final design. The "notouch time" is the minimum cool down the temperature during short maintenance without wax mitigation process.

5. Start-up: wax deposition can solidify before start-up. Also, gas expansion into the low-pressure system during well opening will result in Joule Thompson cooling, thus jeopardizing material integrity and causing wax formation.

6. Well Shut-in: For short-duration shut-ins that may be due to host facility shut-in, the insulation type should slow the cooling process and allow the wells to be re-started without initiation of full shut-down.

\section{Conclusions}

Several multiphase simulations were carried out in this work using PIPESIM software to investigate the effects of flowline sizes, flow rates, insulation material, type and configuration on flow assurance of waxy crude over 10.2 $\mathrm{km}$ between the wellhead and the first stage separator on the platform. Considering the implications of these factors for flow assurance. The data and results obtained from this study suggest that line size of $0.29 \mathrm{~m}$, the flow rate of $3280 \mathrm{~m}^{3} / \mathrm{d}$, poly-urethane foam, and pipe-in-pipe insulation type are favourable to flow assurance of waxy crude with respect to maintaining the temperature of the fluids above the wax appearance temperature of $26^{\circ} \mathrm{C}$ and also to deliver the fluids to the platform at the recommended pressure of over 11 bar. Obviously, temperature drop during unsteady-state operation is very critical for wax deposition, and this makes it imperative that reliable insulation material is used for the flowline design to ensure that the temperature of the fluids within the system stays above the wax appearance temperature. 1n 2014, Marcia et al. concluded from their work that flow from wellhead to the platform with both pipe lengths of $5 \mathrm{~km}$ and $20 \mathrm{~km}$ resulted to outlet temperature of $19.66^{\circ} \mathrm{C}$ which was below their estimated wax appearance temperature. With transient operations like start-up and shutdown, more challenges have to be managed because temperatures will often be lower than that of steady-state condition, thereby causing wax deposition risks.

From the PIPESIM simulations done in this work, it is very evident that the use of polyurethane foam insulation is highly thermally efficient for keeping the temperature of the fluids within the system above wax appearance temperature and flowing the fluid without wax deposition and plugging. A safety factor of $4-5^{\circ} \mathrm{C}$ must be added to the estimated wax appearance temperature for the outlet temperature value to be used in the insulation design to operate outside the wax deposition zones safely.

\subsection{Recommendations}

It will be recommended that the multiphase flow simulations be carried out for projects involving longer subsea flowlines than the $10.2 \mathrm{~km}$ flowline length considered in this work. This will help determine the optimal flowline lengths for insulation as a strategy for wax mitigation. Moses (2013) in his work concluded that $200 \mathrm{~km}$ is the longest pipeline length optimally viable for pipe insulation, above $200 \mathrm{~km}$, pipeline insulation becomes uneconomical, hence, the need to consider flowing waxes with the recovered fluids. Marcia et al. (2014) also concluded that the shortest pipe length viable for insulation is $5 \mathrm{~km}$; below this length, the use of insulation becomes uneconomical. Cognizant to this, and to validate the results from this work, there is a need to perform replicate simulations in the future, with longer flowline lengths, different flow rates and flowline sizes from the ones considered in this work. Transient analysis can also be considered to capture wax deposition tendencies during shut down and restart scenarios. Investigations can also be done using inline heating methods to ascertain their effectiveness as a standalone and synergistic option for the flow of waxy oils.

Before now, there were limited efforts to investigate the synergistic impact of factors such as flow rate, flowline size, water cut, insulation configuration, overall heat transfer coefficient, slugging, and transient operations on the wax deposition. Sequel to this, this work focuses on analyzing the above factors on waxy crude transportation via multiphase simulations using PIPESIM ${ }^{\circledR}$. The MatLAB ${ }^{\circledR}$ code developed also presents a good avenue for insulation thickness estimation for waxy crude transportation over long distances.

\section{References}

Abarasi, H. (2014). A review of technologies for transporting heavy crude oil. J Petrol Explor Prod Technol, 4:327-336.

Adeyanju O.A. and Oyekunle L. (2013). Experimental study of wax deposition in a single-phase subcooled oil pipelines. NAICE. Lagos, Nigeria. 
Aiyejina A., Dhurjati P.C., Angelus P., and Sastry M. (2011). Wax formation in oil pipelines: A critical review. International Journal of Multiphase Flow, 37(7), pp.671-694.

Allan B.H. and Augustin D. (2000). Cost-Effective Thermal Insulation Systems For Deepwater. Offshore West Africa Conference and Exhibition.

Abidjan, Cöte d'Ivoire. Bai, Y. \& Bai Q. (2005). Subsea Pipelines and Risers. Oxford: Elsevier Science Ltd, pp 263-377.

A. Ansari, N. D. Sylvester, O. Shoham, J. P. Brill, A Comprehensive Mechanistic Model for Upward two-phase flow in Wellbores, SPE 20630, SPE Annual Conference. 1990

Bai, Y. \& Bai Q. (2012a). Subsea Engineering Handbook. USA: Elsevier Inc., pp. 401-451.

Bai, Y. \& Bai Q. (2012b). Subsea Engineering Handbook. USA: Elsevier Inc., pp. 483-504.

Becker, J. (2007). Crude Oil Waxes, Emulsions, and Asphaltenes. Liverpool: PennWell Corporation.

Beggs, H. D., and Brill, J. P., (1973). A study of Two-phase Flow in Iclined Pipes, Journal of Petroluem Technology vol. 25 (No. 5) (1973) 607-617.

Bjørnstad, B. (2004). Direct Heating Avoids Flowline Fouling. Umbilical Cables. Nexans, Norway.

Accessed from http://www.epmag.com/ 3 August 2018

Bouchonneau N., Franche-Comte U., and Sauvant-Moynot V. (2007). Thermal Insulation Material for Subsea Pipelines: Benefits of Instrumented Full-Scale Testing To Predict the Long-Term Thermomechanical Behaviour. Offshore Technology Conference, (p. OTC 18679). Houston, Texas. Brill, J. P. and Mukherjee, H (1999). Multiphase flow in wells, monograph vol. 17 (1999), L Henry. Doherty Series, Society of Petroleum Engineers, Richardson, Texas.

Candelier C., Durica S., and Beys F. (2015). Subsea Pipeline Electrical Heat Trace (EHT) - “Active” Heating Application For A Deep Water Brown Field Development. 12th Offshore Mediterranean Conference and Exhibition. Ravenna, Italy: OMC 2015 Programme Committee.

Chen, J., Zhang J., and Li H. (2003). Determining the wax content of crude oils by using differential scanning calorimetry. Beijing: Department of Petroleum Storage and Transportation, University of Petroleum, Changping District.

David, V. (2013). Flow Assurance: Heat Transfer. Accessed from Blackboard: https://abdn.blackboard.com/bbcswebdav/pid-639088-dt-content-rid811929_1/courses/MGD_EG55F8

_EG55G8_13/Lecture\%206\%20Heat\%20Transfer.pdf 15 September 2018

Delebecque L., Sibaud E., Scocard M., Rueda C., and Delbene P. (2009). How to overcome challenges with active electrical heating in deepwater - Offshore. Accessed from http://www.offshoremag.com/articles/print/volume-69/issue-2/flowlines-amp-pipeline/howto-overco me-challenges-with-activeelectrical-heating-in-deepwater.html 9 September 2018

Dwivedi P., Sarica C. and Chang W., (2013). Experimental Study of Wax deposition Characteristics of a Waxy Crude oil under Single-Phase Turbulent Flow Condition. Offshore Technology Conference (pp. pp. 61-73). Houston, Texas.

Elijah T., John O., and Tinuade A. (2012). Crude Oil Transportation: Nigerian Niger Delta Waxy Crude. Accessed from www.intechopen.com 12 September 2018

Girma T. C., Shaharin A. S., and Azuraien J. (2018). Flow start-up and transportation of waxy crude oil in pipelines-A review. Journal of Non-Newtonian Fluid Mechanics, 251, pp 69-87.

Golczynski, T.S. and Kempton, E.C. (2006). Understanding Wax Problems Leads to Deepwater Flow Assurance Solutions. World Oil Magazine, Vol. 227, No. 3. http://www.worldoil.com (Accessed 20 August 2018).

Gudmundsson, J. (2002). Cold Flow Hydrate Technology. 4th International Conference on Gas hydrates. Yokohama.

Hasan, S.W., Ghannam M.T., and Esmail N. (2010). Heavy crude oil viscosity reduction and rheology for pipeline transportation. Fuel, 89(5), pp.1095-1100.

Heggdal, O. (2012). Electric Heating of Pipelines and Large Export Flowlines $>30$ " and more than $100 \mathrm{~km}$. Offshore Technology Conference. Houston, Texas, USA, p. OTC 23646.

Hoffmann, R. (2012). Longer and Colder: Wax Control for Long Step-Out Distances. Statoil Presentation at SPE FA Workshop, (pp. pp 4-10). Norway.

Huang Z., Zheng S., and Fogler H. (2015). Wax deposition: Experimental Characterizations, Theoretical Modeling and Field Practices. CRC Press. Hyne, N. (2012). Nontechnical Guide to Petroleum Geology, Exploration, Drilling, and Production. Coventry: Pennwell Books. Incropera

F., Dewitt D., Bergman T., and Levine A. (2007). Fundamentals of Heat and Mass Transfer. The USA. International Energy Agency (2018). World Energy Outlook 2018. Accessed from https://www.iea.org/weo2018. 15 July 2018.

J. J. Xiao, O. Shaham, J. P. Brill, (1990). A Comprehensive Mechanistic Model for two-phase flow in Pipelines, SPE, (1990). SPE 20631

Jung, S., Lee D., and Lim, J. (2014). A Simulation Study of Wax Deposition in Subsea Oil Production System. 
Twenty-fourth International Ocean and Polar Engineering Conference (pp. pp. 25- 30). Busan, Korea: International Society of Offshore and Polar Engineers.

Kang, P., Lee D., and Lim, J. (2014). Status of Wax Mitigation Technologies in Offshore Oil Production. The Twenty-fourth International Ocean and Polar Engineering Conference (pp.31-38). Busan, Korea: International Society of Offshore and Polar Engineers.

Kelechukwu E.K., Hikmat A., and Ahmmed S. (2013). Prediction of Wax Deposition Problems of Hydrocarbon Production System. J. Pet. Sci. Eng., 108 (2013) 128-136.

Khresno, S. (2010). Gas Lift and Wax Problem. Oxford: Oxford University Press. Kjøraas, M. (2012). Modeling of Wax Deposition in Subsea Pipelines. Trondheim, Norway.

Kliewer, G. (2008). Subsea Processing/Boosting Choice for Deep, Ultra Deep, Harsh Environment Production. Offshore Magazine Publication, pp. Vol. 68, Issue 10.

Kondapi, P. and Moe, R. (2013). Today's Top 30 Flow Assurance Technologies: Where Do They Stand? Offshore Technology Conference, (p. OTC 24250). Houston, Texas.

Kulbotten, H. and Lervik J.K. (2007). Direct Electrical Heating System for Preventing Wax and Hydrates in Pipelines. Trondheim, Norway: SINTEF Energy Research.

Kulbotten, H. (2008): Direct Electric Heating (DEH) - Basic Technology. SINTEF Energy Research, Presentation at TEKNA, pp 8-21.

Larsen R., Lund A., Argo C., and Makogon T. (2007). Cold Flow - A Simple Multiphase Transport Solution for Harsh Environments. 18th International Oil Field Chemistry Symposium.

Geilo, Norway. Lee, H. S. (2008). Computational and Rheological Study of Wax Deposition and Gelation in Subsea Pipelines. USA: University of Michigan.

Lenes A., Lervik J.K., Kulbotten H., Nysveen A., and Bornes A. (2005). Hydrate Prevention on Long Pipelines by Direct Electrical Heating. Proceedings of the Eleventh International Offshore and Polar Engineering Conference. Seoul, Korea: ISBN 1-880653-64-8.

Lyons W. C., Plisga G.J., and Lorenz M.D. (2016). Standard Handbook of Petroleum and Natural Gas Engineering. Elsevier.

Marcia C.K., Adriana T., Lenise C.V., Rogerio M.C., and Alexandro B.M. (2014). Flow Assurance Challenges For Long Subsea Pipelines. Rio Janeiro: Conference Paper, Rio Oil \& Gas Expo and Conference.

Marcia C. Adriana T. and Lenise C., (2012). Flow Assurance Study for Waxy Crude Oils. Energy Fuels, 26, 26882695.

Mcdermott, P. and Sathanathan R., (2014). Active Heating for Life of Field-Flow Assurance. Offshore Technology Conference. Houston, Texas, USA: OTC-25107.

Moses E. A. (2013). Cold Flow In Long-Distance Subsea Pipeline. Norway: Norwegian University of Science and Technology.

Mukherjee, H., and Brill, J. P. (1985). "Pressure Drop Correlations for Inclined Two-Phase Flow." ASME. J. Energy Resour. Technol. December 1985; 107(4): 549-554.

Nava, Z., Rojas, M., Martinez, N., Trujillo, J., Rigual, Y., and Gonzalez, C. (2011). Hydraulic Evaluation of Transport Gas Pipeline on Offshore Production. Intl. Petr. Tech. Conference, Bangkok, Thailand. IPTC 15287.

Netzsch. (2010). DSC Instruments, Temperature and sensitivity calibration. Software Manual.

Nufarah H.B. and Pao, W. (2016). Optimum Thermal Insulation Design for Subsea Pipeline Flow Assurance. Accessed from https://www.researchgate.net/publication/311911773 13 September 2018 Nysveen A., Kulbotten H., Lervik J.K., Bornes A.H., and Hoyer H. (2007). Direct Electrical Heating of Subsea PipelinesTechnology Development and Operating Experience. IEEE Transactions On Industry Applications, Vol. 43, No. 1, pp 118-129.

Olusiji, A. and Layioye O. (2013). Experimental Study of Wax Deposition in a Single-Phase Subcooled Oil Pipelines. Nigeria Annual International Conference and Exhibition. Lagos, Nigeria: Society of Petroleum Engineers.

Oseghale C.J., Akpabio E.J., and Ededor O. (2012). Mitigating Potential Risk of Paraffin Wax Deposition on Oil Pipelines in Niger Delta. Journal of Engineering and Applied Science, 7, 348-352.

Parman, D.G., Ojeda S.S., Marron A., and Roskold K. (2013). Case Study: Heating Offshore Production Tubing Electrically for Crudes that Have Wax Issues. Offshore Technology Conference. Houston, Texas, USA: Offshore Technology Conference.

Ratnadip R., (2017). Modeling and Simulation of Wax Deposition in Crude Oil Pipeline. International Journal of Engineering Research and Technology, ISSN 0974-3154 Volume 10, Number 1.

Rosvold, K. and Gudmundsson J.S. (2008). Wax Deposition Models. Norway: Norwegian University of Science and Technology.

Roth, F. (2011). Direct Electrical Heating of Flowlines-Guide to Uses and Benefits. Offshore Technology Conference. Rio de Janeiro, Brazil: OTC. 
Roth R., Voight R., and DeGeer D. (2012). Direct Electrical Heating (DEH) Provides New Opportunities for Arctic Pipelines. Offshore Technology Conference. Houston, Texas, USA. Schlumberger. (2011). Pipesim Quick Reference Guide. Accessed from https://abdn.blackboard.com/bbcswebdav/pid-644570-dtcontentrid\%2032775_1/courses/MGD_EG55 F8_EG55G8_13/PIPESIM_Quick_Reference_Guide\%2 81\%29.pdf 13 September 2018

Semenov, A. (2012). Wax Deposition Forecast. SPE North Africa Annual Technical Conference and Exhibition (p. SPE 149793). Cairo, Egypt: Society of Petroleum Engineers.

Siljuberg, M. (2012). Modelling of paraffin wax in oil pipelines. Norwegian University of Science and Technology.

Singh, A., Lee H., Singh P., and Sarica C. (2011). Flow assurance: Validation of wax deposition models using field data from a subsea pipeline. Proceedings of Offshore Technology Conference (pp. 1-19). Stubsjoen, M. (2013). Analytical and Numerical Modeling of Paraffin Wax in Pipelines. Norwegian University of Science and Technology.

Sulaimon G., Falade K., and DeLandro W. (2010). A Proactive Approach for Predicting and Preventing Wax Deposition in Production Tubing Strings: A Niger Delta Experience. Acad. J., 1: 26-36. Sun-Young J., DongGun L., and Jong-Se L. (2014). A Simulation Study of Wax Deposition in Subsea Oil Production System. Proceedings of the Twenty-fourth International Ocean and Polar Engineering Conference.

Busan, Korea Tarantino G. B., Vieira L. C., Pinheiro S.B., Mattedi L.C., and Santos L. (2016). Characterization and evaluation of Waxy Crude Oil Flow. Brazilian Journal of Chemical Engineering, Vol. 33, No. 04, pp. 1063 - 1071.

Theyab A.M. and Pedro D. (2016). Experimental study of wax deposition in the pipeline - effect of inhibitor and spiral flow. International Journal of Smart Grid and Clean Energy, Vol. 5, No. 3.

Theyab A.M. and Pedro D. (2016). Experimental Study on the Effect of Inhibitors on Wax Deposition. J Pet Environ Biotechnol, Volume 7, Issue 6.

Turner, D. and Talley L. (2008). Hydrate Inhibition Via Cold Flow - No Chemicals or Insulation. Proceedings of the 6th International Conference on Gas Hydrates.

Vancouver: ICGH. Tvedt. (2005). Transportation of Petroleum in Subsea Pipeline - A Comparative Analysis. Trondheim: NTNU. Venkatesan R. and Creek J.L. (2007). Wax Deposition during Production Operations. Offshore Technology Conference.

SOTA. Vikas, M. and Ajay K. (2013). Effect Of Several Parameters On Wax Deposition In The. International Journal of Applied Engineering Research and Development, ISSN 2250-1584, Vol. 3, Issue 4, 1-10.

Wolden, M. (2008). Cold Flow for Very Long Multiphase Transportation Pipelines. Norway: SINTEF Petroleum Research.

Yukie, T. (2014). Flow Assurance: Two-Phase flow and flow pattern maps. Accessed from https://abdn.blackboard.com/bbcswebdav/pid-631779-dt\%20contentrid\%201793704_1/courses/MGD EG55F8_EG55G8_13/multiphase\%20flow\%20- \%20patterns\%20MyA\%281\%29.pdf. 20 August 2018.

Yukie, T. (2014). Flow Assurance: Pressure changes in two-phase flow. Accessed from https://abdn.blackboard.com/bbcswebdav/pid-634598-dt-content-rid1800674_1/courses/MGD_EG55F 8_EG55G8_13/multiphase\%20flow\%20- \%20pressure\%20loss\%20MyA.pdf. 25 August 2018

Zhang Y.L. and Liu T. (2016). Isolation and characterization of a novel paraffin wax-degrading bacterium, Pseudomonas sp strain PW-1, from petroleum-contaminated sites. Daqing, Heilongjiang, China: Agricultural College, Heilongjiang Bayi Agricultural University.

Zhenyu H., Hyun S.L., Michael S., and Scott F.H. (2011). A Fundamental Model of Wax Deposition in Subsea Oil Pipelines. American Institute of Chemical Engineers Journal, Vol. 57, No. 11.

Zhenyu H., Michael S., Ravi K., and Scott F.H. (2010). Wax Deposition Modeling of Oil/Water Stratified Channel Flow. Accessed from Wiley Online Library: DOI 10.1002/aic.12307. 2 September 2018 